\title{
Some experiences from an optics master of science degree
}

\section{Angel Augier Calderin, Adriana Mavilio, Agueda Garcia}

Angel G. Augier Calderin, Adriana Mavilio, Agueda Garcia, "Some experiences from an optics master of science degree," Proc. SPIE 3831, Sixth International Conference on Education and Training in Optics and Photonics, (16 June 2000); doi: 10.1117/12.388724 


\title{
Some experiences about an Optics Master of Science degree
}

\author{
Angel G. Augier, Adriana Mavilio, Agueda García \\ Lab. of Coherent Optics, Dept. of Physics, Polytechnical Institute "José A. Echeverría" (ISPJAE) \\ CP 19390, Havana, CUBA
}

\begin{abstract}
About forty university graduates have completed their specialized studies in Optics. These specialized studies enable their successful development in their professional tasks in national Cuban institutions. In the conception of the Optics Master of Science degree plan, professional improvement is considered regarding the accumulated experience, the training requirements of human resources, as well as the contemporary world development trends.
\end{abstract}

Keywords: Optics, Photonics, light, Master of Science, education and training program, laser technological applications

\section{INTRODUCTION}

Optics and laser techniques are considered fields of enormous current and future application possibilities. Some examples are the development of many different laser instruments, optical equipment, optical measuring experimental techniques and non destructive testing, technological applications of laser in the treatment of materials, development and use of materials with new optical properties and optical sensors, use of sources of light and optical fibers in telecommunications and in electronics in general, and other applications.

In the sciences of life, such as Biology, Medicine, Biotechnology and Bioengineering, there are numerous possibilities of using light and especially laser light, not only for specific uses but also for their possibilities of unchaining positive processes in biological mediums.

There exist some centers of recognized national experience and prestige in this field, in Cuba, such as the Department of Physics at the Polytechnical Institute "José Antonio Echeverría" (ISPJAE), the Institute of Materials and Reagents (IMRE) and the Faculty of Physics at Havana University, the National Center of Scientific Investigations (CENIC), and the Center of Development of Equipment and Scientific Instruments (CEDEIC).

The increase in the scientific and educational collaboration links with Latin American professors and researchers and with professionals all over the world, makes necessary the consolidation of the academic formation quality of university graduates from Cuban universities covering this branch.

This Optics Master of Science program is part of a training system of highly qualified human resources anteceded by the program of academic undergraduate, and being continued by the Ph.D. degree programs.

Considering the antecedents of the Optics, Laser-Holography Specialist program, offered at ISPJAE in 1979 as study of graduate degree, as well as the necessities concerning the academic formation of graduate degree, it was required the designing and organization of a new and up to date course by the institutions covering this field. As a result it was designed the Optics Master of Science academic degree program ${ }^{1}$, including the most positive ideas of previous studies. This program was designed, structured and offered by ISPJAE, at the Ministry of Higher Education, with the collaboration of the CEDEIC at the Ministry of the Science, the Technology and the Environment of the Republic of Cuba and other institutions. The present paper shows the contents of this Master level and some of the experiences obtained at the two first editions of these Master studies.

The conception and scientific level of this MSc. program is in accordance with the existing ones in the national ${ }^{2}$ and international ${ }^{3,4,5}$ Physics or Optics Master of Science programs. 


\section{ENTRANCE AND PROFILE OF GRADUATE}

The Optics MSc. program is directed to the interests of graduates of the Faculty of Physics or other specialities of Sciences, Engineers specialized in any Technical Sciences or graduates of the Higher Pedagogical Institute in the Speciality of Physics. The graduates acquire a specialized formation in general Optics through compulsory subjects to be studied, and some more specific branches, according to the line, terminal profile or central topic selected by students through their enrollment in optional courses. This line will be deepened by a research work guided by a qualified tutor. A thesis constitutes the culmination of these studies. Thereby the graduate will be prepared to face successfully the application of the most modern techniques in the solution of scientific and technical problems in this multiprofessional branch of Science and Technology.

\section{SYSTEM OF OBJECTIVE AND PROGRAM STRUCTURE}

The objectives keep in mind the formation of high level graduates able to:

1. Apply advanced knowledge of Optics in some of their specialized branches.

2. Apply the scientific method in the formulation and solution of scientific-technical problems in these branches, from the theoretical point of view as well as the experimental one.

3. Exploit the techniques and equipment based on the Optics and laser phenomenon in industries, research centers and universities.

4. Apply an interdisciplinary approach in the different areas where Optics and laser techniques may be used.

5. Acquire the domain of some fundamental techniques of digital computation and their applications in Optics.

To these ends, the Optics MSc. program is structured around the following central topics:

Formation and processing of images and signals; Metrology; Photobiology and Photomedicine; Photometry, Sources of light and optical sensors; Development of systems and optical instruments; Optics and laser engineering applications; Theoretical and experimental advanced Optics.

These central topics are in correspondence with the main lines of research and development of the Cuban institutions concerning the area of Optics, laser techniques and their applications. The plan is structured in three fundamental steps:

*Compulsory subjects

*Optional subjects

*Scientific research work and MSc. thesis presentation

Each subject will be determined by its function in the program and its correspondence with the central topic selected by the applicant, as well as the possibilities of implementation of experimental activities. In a general way the following considerations should be kept in mind.

- The compulsory subjects contribute to deepen and bring up to date the basic knowledge of the professional formation, lectures, practical classes, guided laboratories and laboratory practices are used. Their duration is in correspondence with the material possibilities of the centers that support the Optics MSc. program.

- The optional subjects support the development of the intellectual autonomy and the generation of knowledge paid to the selected central topic; for their development not only lectures but also lab practices and laboratory practical classes are used. Seminars are used for the discussion and scientific debate of diverse up to date topics linked to the research lines of the centers, in general, and of the educational ones that teach them specifically.

- The implementation of the final research project of the master studies guided by a tutor, culminates with the MSc. thesis presentation in front of a competent board constituted by three members and an applicant counterpart. During this process special attention will be granted to the application of the acquired knowledge, to the generation of new knowledge in the selected theme, and to the development of the intellectual autonomy of the applicants in the technical and methodological order. The thesis is written using a text editor, following the rules for the national Ph.D. 
thesis, except in that the MSc. thesis must have an approximate extension of 50 pages.

\section{EVALUATION SYSTEM}

The evaluation system of the program will be carried out in correspondence with the nature, objectives and methodology used in the different educational activities as well as their functions in the several steps of the plan. Regarding courses, evaluations are carried out by means of tests, tasks, seminars and laboratory practices. An Academic Committee specifies the evaluation system considering the professor's proposal at the right time. To pass the plan and get the Optics Master of Science degree, it is required to obtain a total minimum of 70 credits. The credits have an approximate equivalence of 15 hours or fraction per credit. These credits are distributed in the following way:

1) A minimum of 40 credits in courses, including compulsory and optional subjects.

2) A maximum of 3 credits for presentation of research works in seminars (1 credit per seminar as maximum).

3) Presentation of works in national and international events organized in our country, $(1$ credit per work, to a maximum of 3 credits).

4) Publications of papers in scientific journals or proceedings of international events. The tutor will grant a maximum of 3 credits for each publication, depending on the applicant contribution in the work. (A total maximum of 6 credits can be obtained for this concept).

5) For the thesis project drafting and presentation, the tutor will grant a total maximum of 30 credits.

The distribution of credits for the compulsory subjects is:

Advanced Optics (3)

Fourier Optics (3)

Non linear Optics (2)

Theory of optical systems (2)

Methods of scientific research (3)

Systems of programs for scientific calculation (3)

The optional subjects are:

Holography; Image processing; Optical measuring techniques; Photobiology and Photomedicine; Design of systems and optical instruments; Optical statistics; Technological applications of laser; Optical communications, MedicalBiological applications of laser; Optical properties of solids; Signal analysis; Stochastic processes.

For each optional subject three credits are granted. In order to obtain the minimum of 40 credits demanded in courses, the applicant should select a minimum of 5 optional subjects. The optional subjects will be grouped into two blocks of the central topics:

BLOCK 1. Central Topics: Formation and treatment of images and signals, Metrology, Theoretical and experimental Optics.

Subjects: Holography, Image processing, Statistical Optics, Optical communications, Analysis of signals, Optical measuring techniques, Design of systems and optical instruments, Stochastic systems and processes, Optical properties of solids.

BLOCK 2. Central Topics: Photometry, Sources of light and optical sensors, Development of systems and optical instruments, Optics and laser engineering applications, Photobiology and Photomedicine.

Subjects: Image processing, Optical measuring techniques, Design of systems and optical instruments, Optical communications, Analysis of signals, Optical properties of solids, Technological applications of laser, Photobiology and Photomedicine, Medical-Biological applications of laser.

The program includes the generalization of the study of scientific work methods, and strengthens the application of the digital computing methods. With the aim of modernizing and improving the MSc. program not only the technical aspects concerning the contents, but also the methodological aspects, related with the modern methods of learning were taken into account. The last edition included an optional previous preparatory course designed to such effect. The subjects to be studied are the following: Windows operative system for users (36 hours); Fundamentals of Optics (36 hours); Elements of Quantum Mechanics (48 hours); Mathematics in Optics and laser Physics (48 hours). 
An applicant should take the previous preparatory courses if the Academic Committee or the applicant himself considers it is necessary.

\section{SOME RESULTS}

Some results of the different education programs in Optics for university graduates that have taken place in our Institute, from 1979 so far are shown below (Tables 1-6). The program of Master of Sciences in this speciality began in 1995 (first edition), and it continues later, in 1998 (second edition). The information includes the approximate composition of participants according to its university specialities, as well as the topics of their corresponding thesis.

Approximately $75 \%$ of the first edition thesis has already been presented with satisfactory results, as long as the remaining ones will be presented in the year in course. The $100 \%$ of the second edition thesis will be presented next year. The selected possible topics of the thesis coincide with the central topics presented in the system of objectives and program structure, considered in the present paper.

\subsection{Laser-Holography Specialist Program (1979 and 1984)}

Table 1. Approximate composition of Specialist Program

\begin{tabular}{|c|c|c|c|}
\hline $\begin{array}{c}\text { No. } \\
\text { Applicants }\end{array}$ & $\begin{array}{c}\text { Graduates } \\
\text { in Physics }\end{array}$ & $\begin{array}{c}\text { Graduates } \\
\text { in Education }\end{array}$ & Engineers \\
\hline 12 & $\mathbf{8}$ & $\mathbf{2}$ & $\mathbf{2}$ \\
\hline
\end{tabular}

Table 2. Topics of Thesis of Specialist Program

\begin{tabular}{|c|c|}
\hline $\begin{array}{c}\text { Formation and processing of images } \\
\text { and signals }\end{array}$ & $\mathbf{8}$ \\
\hline $\begin{array}{c}\text { Development of systems and optical } \\
\text { instruments }\end{array}$ & 2 \\
\hline $\begin{array}{c}\text { Optics and laser engineering } \\
\text { applications }\end{array}$ & 2 \\
\hline
\end{tabular}

\subsection{Optics Master of Science Program (First Edition. Jan-1995)}

Table 3. Approximate composition of Optics Master of Science Program (First Edition)

\begin{tabular}{|c|c|c|c|}
\hline $\begin{array}{c}\text { No. } \\
\text { Applicants }\end{array}$ & $\begin{array}{c}\text { Graduates } \\
\text { in Physics }\end{array}$ & $\begin{array}{c}\text { Graduates } \\
\text { in Education }\end{array}$ & Engineers \\
\hline 12 & $\mathbf{8}$ & $\mathbf{1}$ & $\mathbf{3}$ \\
\hline
\end{tabular}


Table 4. Topics of Thesis of Optics Master of Science Program (First Edition)

\begin{tabular}{|c|c|}
\hline & 3 \\
\hline Formation and processing of images and signals & 2 \\
\hline Metrology & 1 \\
\hline Sources of light and optical sensors & 3 \\
\hline Development of systems and optical instruments & 3 \\
\hline Optics and laser engineering applications & 2 \\
\hline
\end{tabular}

\subsection{Optics Master of Science Program (Second Edition. Jan-1998)}

Table 5. Approximate composition of Optics Master of Science Program (Second Edition)

\begin{tabular}{|c|c|c|c|}
\hline $\begin{array}{c}\text { No. } \\
\text { Applicants }\end{array}$ & $\begin{array}{c}\text { Graduates } \\
\text { in Physics }\end{array}$ & $\begin{array}{c}\text { Graduates } \\
\text { in Education }\end{array}$ & Engineers \\
\hline 13 & 7 & 5 & 1 \\
\hline
\end{tabular}

Table 6. Topics of Thesis of Optics Master of Science Program (Second Edition)

\begin{tabular}{|c|c|}
\hline Formation and processing of images and signals & 4 \\
\hline Metrology & 1 \\
\hline Photobiology and Photomedicine & 1 \\
\hline Sources of light and optical sensors & 1 \\
\hline Development of systems and optical instruments & 4 \\
\hline Optics and laser engineering applications & 2 \\
\hline
\end{tabular}

\section{CONCLUSIONS}

The application of this MSc. program constitutes a qualitative jump with respect to the studies of graduate degree in Optics previously taught in our country. As a consequence of the application of these education programs in Optics, about forty university graduates have completed their academic basic formation in this field enabling them so far to develop successfully their professional work in the several centers and national institutions.

In the conception of the program a professional continuous improvement is considered, regarding the accumulated experiences in each previous edition, the training requirements of human resources in the national environment, as well as the contemporary world development trends in the branches of Science and Technology.

This Optics Master of Science program is of great importance in the national educational context, being part of a system of highly qualified human resources training anteceded by the program of academic undergraduate, and being continued by the $\mathrm{Ph} . \mathrm{D}$. degree programs.

More than a 70\% of the professor's staff is formed by Ph.D. Professors and researchers from ISPJAE, as well as from other national research centers concerning this area, participate as lecturers in the teaching of these MSc. degree subjects. 
All this has contributed to create a strong increasing interrelation between applied investigation, education, and production.

\section{REFERENCES}

1. Programa de Maestría en Óptica. Departamento de Física, ISPJAE, La Habana, Cuba, 1996.

2. Programa de Maestría en Ciencias Físicas. Facultad de Física, Universidad de La Habana, La Habana, Cuba, 1996.

3. Programa de Maestría y Doctorado en Óptica. Centro de Investigación Científica y Educación Superior de Ensenada (CISESE). Ensenada B. C. México, 1995.

4. Optical Electronics. MSc. University of Strathclide, Canada, 1995.

5. Physical Methods of Materials Characterization. MSc. University of Warmick, U.K, 1995. 